lijksheidsgevoel, met zijn beroepsopvatting of met zijn eer en geweten. Maar waartoe dit alles, als een meer logische en prineipiecl juiste oplossing voor de hand ligt?

$1 k$ geloof niet aan andere voordeelen van den internen accountant boven den public-accountant dan het „kostenvooldeel",indien dit bịj gelịjke vaktechnische uitoefening der functic al mocht bestaan. Ook de door den heer Zu'art in dit opzicht gebozigde argumenten. zooals de meerdere ervaring in de branche of het in meerdere mate ter beschikling staan van de kartolleiders, houden naar mijn inzicht geen steck; ervariig vlocit uit de uitocfening d.er contrôle-functie vanzelf in voldoend tempo voort en gemis aan de noodige medewerking is aan de samenwerking met den public-accountant geenszins inhaerent.

H. R. REDER

LITERATUUR
Red. Drs. S. KLEEREKOPER
(Bijdragen en mededeelingen zende men aan den Secretaris der
Redactie)

\section{De voorraadcontrôle in de literatuur}

Wij willen onze ,literatuurrubriek" vervolgen met een bespreking van de verschillende opinies, die men in de literatuur over het onderwerp ,voorraadcontrôle" kan aantreffen.

Het is den lezcrs van deze rubriek bekend, dat de verschillende stroomingen, die wij in onze vakliteratuur aantreffen, te dezer plaatse steeds eritisch worden bekeken. Dit „eritische bekijken" beteekent niet een bij voorl)aat veroordeelen van iedere opinie, dic men tegenkomt, mar wel cen vergelijken van alle opinies met één bepaalde zienswijzc, die men op grond van theoretische en practische overwegingen als de meest juiste meent te moeten aanvaarden.

Het is juist in de vergelijling van de verschillende stroomingen, onderling en met een bepaald vast uitgangspunt, dat von' studenten en studeerenden de grootste waarde van een critische analyse van iedere controverse moet worden gezien. Dat ik dit alles bij de voorbereiding van het onderhavige literatuur overricht nog eens in het bijzonder betoog, vindt zijn oorzaak in het feit, dat, naarmate de literatuur vager is in het motivecren van haar verschillende conclusies, cen scherpe vergelijking met een vast omlijnd standpunt noodzakelijker wordt.

En nu is het zoo gesteld, dat in het bijzonder ten aanzien van het uiterst belangrijke probleen van de voorraadcontrôle onze auteur's zich dikwijls vergenoegen met het lanceeren van onbewezen of onvoldoend bewezen, min of meer vage beweringen en dit hecft weer ten gevolge, dat juist hier een scherp markeeren van een eigen nitgangspunt wel heel noodzakelijk is, indien men terminste niet wil vervallen in het steriel opsommen van eenige opinies, die elkaar gedecltelijk bevestigen en gedeeltelijk tegenspreken en die den studeerenden aanstaanden vakgenoot eigenlijk niet anders dan steenen voor brood geven.

Dit alles dient ter verontschuldiging van de betrekkelijk lange jnleiding. die het eigenlijke literatuuroverziclit zal voorafgaan on die dit voorbereidende artikel geheel in beslag zal nemen.

$\mathrm{Bij}$ de critische bespreking van het onderwerp zal ik mij baseeren op de opvattingen van de Amsterdamsche School van welke opvattingen hieronder een resumé volgt. Bij dit resumé zal dan het algemeene uitgangspunt van de School n.l. de theorie van het gewekte vertrouwen als bekend worden veronderstcld, althans niet expliciet worden ontwikkeld.

De algemeene vraag, die bij de eischen, waaraan de voorraadcontrôle moet voldoen een bijzondere rol speelt, is, zooals als algemeen bekend mag worden geacht, die naar de techmische kennis van den accountant.
De vraag Iuidt: in hoeverre ontslaat de omstandigheid, dat de accountant nu eenmaal uiterard als regel slechts deskundige in eigen beroep is, hem van de verplichting tot het verrichten van allerlei contrôlehandelingen, w'aarvoor speciale u'aren-en technielienkennis onmisbar is, zonder dat tengevolge hiervan de functie van het vervullen van de accountantscontrole als gehcel illusoir moet worden beschouwd?

De Amsterdamsche School gecft op deze algemeene zeer principicele vraag het volgende antwoord.

Wil het vervullen van de controlefunctie niet geheel illusoir worden - of om het in duidelijk en ondubbelzinnig Nederlandsch te zeggen: wil het vervullen van de controlefunctie niet cen schijnhandeling worden, die oeconomisch niet rechtvaardigt, dat men er geld an ten koste legt - , dan is het in icder geval noodzakelijk, dat de accountant de verschijnselen, dic zich in de gccontroleerde bedrịjshuishouding afspelen zoo kan begrijpen en waardecren, dat hem een (juantitatieve voorstelling ervan mogelijk wordt.

En hieruit volgt, dat een zeliere mate van technische- en uarenkennis t.o.v. de door hcm gecontröleerde bedrïfshuishoudingen, als volstrelit onmisbar moet u'orden beschouwd, al kan overigens uorden toegegeven, dat in bepaalde gevallen deze kennis wel tot een vitcrst minimum kan worden beperkt.

Het is inderdaad ecn opgave van de theoric om den noodzakelijken onvang van deze kennis zoo goed mogelijk te benaderen.

We begimnen dan met als conclusie voorop te stellen, dat technische specialisatic niet noodig moet worden geacht en dat dit cigenlijk een standpunt is, dat - zoolang maar niet over voorraadcontrôle wordt gesproken - door de groote meerderheid van vakgenooten, door de manier waarop zij hun controles uitocfenen, impliciet wordt aanvaard. In waarheid is het toch zoo, dat men bij het aanvaarden van iedere contrôle, zoowel als l,ij het samenstellen van jeder inrichtingsrapport, begint met het maken van een grondige studie van de techniek van de onderhavige bedrijfshuishouding.

In dezen algemeen anvarden eisch liggen twee erkenningen zeer positief opgesloten en wel:

$1^{\circ}$ een zekere mate van technologisch inzicht is voor den accountant onmisbaar.

$2^{\circ}$ specialisatie op dit terrein van kennis is niet noodzakelijk.

Dit practische gegeven ontslaat ons niet van den plicht om deze twce stellingen theoretisch aannemelijk te maken; het zou immers kummen zijn, dat de practijk hier irrationcele grontbeginselen zou hebben aanvaard.

Wat betreft de eerste stelling n.l. de bewering, dat een zekere mate van technologisch inzicht onontbeerlijk is lijkt het mij, dat geen tegenspraak te duchten is.

De waarheid hiervan lijkt zoo evident en wordt bovendien zoo algemeen erkend, dat alhoewel een klemmend betoog hier gemakkelijk geleverd kan worden, ik dit punt met stilzwijgen zal voorbij gaan.

Meer questieus is het probleen, lat in de tweede stelling ligt opgesloten: als technologisch inzicht noodzakelijk is, is dan specialisatie op dit gebied niet gewenscht?

Het gevaarlijkste gebruik, dat van dit vraagpunt kan worden gemaakt, is wel het volgende:

IIen begint eerst met het punt 1 (technologisch inzicht is noodig) toe te geven. Vervolgens leidt men hicruit af, dat cen speciale opleiding op dit gebied noodig zou zijjn teneinde daarna te constatceren, dat deze opleiding den accountant ontbreckt. Hieruit zou dan volgen, dat ook het zoo noodige technologische inzicht niet aanwezig kan zijn en dan heeft men het punt bereikt, dat men zoekt. $\Lambda$ ls inderdaad het zoo noodige technologische inzicht niet aanwezig is, dan zullen ook allerlei contrôlehandclingen, waar dit inzicht voor noodig is achterwege 
dienen te blijven. En dit argument wordt dan op de spits gedreven bij de controle van den voorraad. Voor controle van den voorraad is veelal warenkennis noodig, deze kemnis ontbeert le accountant. dus rationcele voorradcontrôle blijft achterwege.

Tóor het theoretische antwoord, dat de Amsterdamsclie School hicrop ten dienste staat, nader te ontwikkelen wil ik vooraf een ander probleem in het kort belichten.

'Toegegeven moet worden, dat voor de contrôle van den voorraad in bepaalde gevallen een zekere mate van technologische liennis noodig is.

Marr evenzeer is het waar, dat voor iedere controle en iedere inrichting een grondige kennis van het bedrijf onontbeerlijk is en dat als het war zou zijn dat gebrek aan technische scholing liet den accountant onmogelijk zou maken om den voor raad te controleeren dit gebrek het hem in de meeste gevallen evenzecr onmogelijk zal maken om rationeel de verantwoording van den gang van het productieproses in algemeenen zin te controleeren. Fn dat het onmogelijk is on zonder technische kennis van de bedrijfshuishouding, die het aangaat, een dragelijk inrichtingsrapport samen te stellon is algemeen erkend. Ik geloof dus, dat hij, die op grond van de technische ondeskundigheid van den accountant een zekere verslapping van cie voorraadcontrôle bepleit, zich aan een zeer ernstige inconsequentie schuldig maakt wanneer hij dan rustig doorgaat met het verrichten vall andere contrôlehandelingen en ontwerpen van inrichtingen, waarroor een soortgelijke kemnis even onontbeerlijk is.

M.i. staat het dan ook volkomen vast, dat als we maar lang genocg doou'gaan met - zooals nog blijken zal geheel ten onrechte - onze ondeskundigheid luide te verkondigen, wij zeer groote deelen van onze beroepsuitoefening aan de ingenieurs zullen moeten afstaan. Deze laatsten zijn wel zoo verstandig om hum eigen ondeskundigheid op administratief en oeconomiseh gebied niet op den voorgrond te schuiven.

Geven we nu in het kort het positieve antwoord van de Amsterdamsche School op de stelling, die ons bezig houdt en die we ten dicnste van den lezer hier nog cens formuleeren:

Ofschoon het vast staat, dat zonder een zekere mate van technologische kennis de accountantsfunctie niet behoorlijk kan worden vervuld, is het niet warar, dat de specialisatie in die richting in het algemeen als noodzakelijk moet worden beschouwd.

Bij de nadere motivecring van deze stelling moeten we allereerst trachten cen misverstand te écarteeren. De accountant, die in ecn bepalde bedrijfshnishouding werkzaam is in de interne controle of een andere intcrne functie vervult, kan in bepaalde gevallen wel degelijk technische specialisatie van noode hebben. Echter is dit niet het probleem, dat ons in de literatuur tegremoet kont; het probleem war deze en dergelijke questies altijd betrekking op hebben is dat van het vervullen van de functie van den openbaren accountant in zijn hoedanigheid dus, als veltrouwensman van het maatschappelijk verkeer.

De Amsterdamsche School motiveert haar afwijzen van technische s p e e a lis a t i e o.a. op de volgende gronden.

Er zijn bepaalde technische en technisch-oeconomische punten ten aanzien warvan de accountant in zijn qualiteit zeker deskundig is. We noemen bij wijze van voorbeelden:

$1^{\circ}$. Vraagstukken van afschrijving. De zoo niterst belangrijke occonomische slijtage brengt mede, dat hier het zwaartepunt niet bij de technicus ligt.

$2^{\circ}$. De meeste organisatorische matregelen. Hierbij is dan verondersteld, dat de accountant de organisatieleer als onderdcel van de hedrijfseconomie, als hoofdvak heeft bestudcerd.

$3^{\circ}$. Vraagstukken vall belegging en financicring. Dit is een gebied van zeer bijzondere technische kennis ten aanzien waarvan de accountant zeker niet minder deskundig behocft te zijn dan de bankier of commissionnair in effecten.

$4^{\circ}$. Er zijn tal van bedrijven ten aanzien wal'van de aceountant q.q. deskundig is lav. trustec-kantoren, beleggings- en finaneicringsbedrijven enz.

We zouden dit lijstje nog geruimen tijd kumnen vervolgen, maar zullen het bij deze enkele voorbeelden, bij wijze van illustratie, laten.

We komen nu tot een eerste conclusie:

De acconntant welit, in zijn qualitcit als zoodanig, in het matschappelijk vorkeer het vertrouwen, dat hij de techniek van bepanlde bedrïfshuishoudingen beheerscht, in dic gevallen, warin die kennis van de techniek uit zijn opleiding als zoodanig volgt.

Hoe nu wanneer deze kennis niet uit zijn oplciding voortvlocit?

Men kan dan van den accountant verlangen dat hij doet hetgeen in zijn vermogen ligt om de onderhavige technick te begrijpen en te beoordcelen. Dit is het vertrouwen, dat hij in het maatschappelijk verkeer opwekt en men moet van hem verlanycn, dat hij zijn functie abandonnecrt wanneer hij door bijzondere omstandigheden (een persoonlijke bijzondere ongeschiktheid on technische verschijnselen te volgen b.v.) dit vertrouwen niet kan dekken.

Meer dan het begrip van den ,verstandigen leek" kan men niet verlangen en hooger is de nolm, dic het verkeer anlegt in geen geval. Dc ervaring leert dan ook, dat deze kennis voldoende is om een rationeele contrôle uit te oefenen.

Dit standpunt is duidelijk, ook ten aanzien van de controle van den voolraad. Het feit, dat men de vraag van de technische kennis in het bijzonder met betrekking tot de voorraadcontrĉle toespitst is aanleiding, dat wij bij dat detailprobleem nog iets langel zullen blijven stilstaan.

Het is noodig om ten aanzien van dit vraagstuk vooraf een nadere onderscheiding te maken.

De warenkennis, die noodig is om goederenvoorraden op te kunnen nemen, heeft in twee richtingen betcekenis.

In de ecrste plaats is de periodieke voorraadopname noodzakelijk teneinde de goederenbeweging van de bedrijfshuishouding in haar geheel te kumnen beoordeelen en in de tweede plaats moet de opname soms geschicden teneinde een belangrijke kapitaakomponent, die op de balans verschijnt te verifieeren. Bepalen we ons allereerst tot het onderzoeken van de functic van het voorraadopnemen in den cerstgenoemden zin - dus met de bodoeling om de algemeene goederenbeweging te controleeren.

We merken dan op, dat in dit verband de voorraadcontrôle slechts een schakel is in de keten van contrôlehandelingen, die het gehcele productieproces moet omsluiten.

Hierbij valt op te merken, dat het hier niet alleen gaat om het begrijpen van de techniek maar om exacte kennis van de warde en hoevcelheid van de onderhavige stof.

Alwecr valt hier op te merken, dat er bepaalde voorraden zijn ten aanzien waarvan de accountant deskundig is (geld, effecten wissels enz.).

$V$ erder zijn er zeer veel soorten voorraden ten aanzien waarvan de leek evengoed kan meten, tellen of wegen als de deskundige (papier, jjzeren staven, fictsen e.d.).

Intusschen is het juist, dat er voorraden bestaan, die de verstandige leek maar niet zonder meer kan opnemen diamanten b.v.).

Maar hier komt dan de gewichtige overweging tot zijn recht, dat men nooit een incidenteele voorraadopname verricht (voor investigations volgt hieronder ecn opmerking) maar dat men bij de voortgezette contrôle steeds de gehecle goederenbeweging op den voet volgt. Men beschikt dus in deze gevallen over de volledige kennis van de volledige administratie d.w.z. over de 
volledige kennis van de verwerving van de goederen en van hun afzet. En zoodoende ontstaat voor die goederen, die men incidenteel niet zou kumnen opnemen de mogelijkheid van tellen, wegen enz. voor den verstandigen leek-accountant. Op deze wijze beschouwd wordt de controle van den voorraad de sluitsteen op de contrôle van de gohecle goederenbeweging en dus op de geheele productie.

Blijft de verificatie van het voorraadeijfer, op ecn of andere wijze achterwege, dan verliest de contrôle op de productie alle beteckenis.

Bovendien echter is - zooals uit onze onderscheiding is gebleken -- de voorraad in vele gevallen een zoo belangrijke groep van kapitaalcomponenten, dat de balans zonder verificatie van dit cijfer nict kan worden gecertificeerd.

Ten aanzien van deze gevallen hreft de accountant zich of te vragen of zijn technische kennis voldoende is om het voorraadcijfer op de balans te verificeren. Als dit onmogelijk is kan hij of geen verklaring afgeven of hij zal zich moeten doen bijstan door een destundige.

Hierbij moet echter wel zecr nadrukkelijk worden vastgestcld, dat in de practijk de gevallen, waarin men inderdaad tot een deskundige zijn toevlucht zal moeten nemen, tot een minimum blijft beperkt en dat iedere theorie, die zich op de noodzakelijkheid van deskundige voorlichting gat baseeren de voor iedere analyse onvergefelijke fout maakt van uitzonderingen tot regel te verheffen. Fen theorie, die dit doet zal inplaats van bij te dragen tot het verhelderen van de begrippen blijken cen sta in den weg te zijn voor het benaderen van de zoo absoluut mogelijk geldende waarheid.

Vatten wij een en ander nog eens samen. (Deze samenvatting is ontleend aan het collegedictaat Limperg) :

$1^{\circ}$,Het gemis aan technische deskundigheid ontheft den ac„, countant niet van de verplichting om zoo ver in de war",ncming van de technische zijde van de verschijnselon te ,gaan als de verstandige leek, gesteund door de admini,,stratieve gegevens; en van de overige kennis van het be"drijf, met nuttig effect voor de contrôle vermag te doen.

$2^{\circ}$ "In dit verband is de verstandige leek iemand, die op het ,normale peil van ontwikkeling en vakstudie staat en die ,over eenig technologisch inzicht beschikt, althans niet de ,gave mist om technologische verschijnselen te begrijpen.

$3^{\circ}$ "De mate van technische deskundigheid, die voor een rede,lijk deskundig effect in de voortgezette controle noodig is, ,,is veelal gering en zeker veel kleiner dan de tegenstanders ,van deze opvatting beweren.

$4^{\circ}$. "Aangezien de accountant met zijn gocdkeurende verkla,ping het vertrouwen wckt, dat ook de voorraadeijfers zijn ,geverifieerd en overigens de voorraden een schakel vormen , in de onverbreckbare keten van de controle van de goede"renbeweging. heeft de accountant slechts de keus tusschen ,ecn voorraadopnemen of het inroepen van de hulp van ,een deskundige, ter cene zijje of wel het abandoneeren , van zịn functie ter andere zịjde.

$5^{\circ}$, "Vnor de controlefunctie is specialisatic niet noodig. Afge,scheiden van de bezwaren overigens aan de specialisatie ,verbonden hebben we te overwegen, dat de accountant ,,met zịjn verklaring slechts het vertrouwen wekt, dat hịj ,,als verstandige leek de techniek van het bedrijf waarneemt ,en kij zou een andere functie gaan vervullen en dienover,eentiomstig een ander vertrouwen wekken indien hij nok ".nls deskundige ging oordeelen."

Ten slotte een enkel woord over investigations.

De gesloten keten, die de controble van de gocderenbeweging ons verschaft, onthreekt hier en in deze gevallen zal het meer voorkomen, dat de accountant zich door een deskundige zal moeten doen bijstaan. Maar zoowel hier, als bij de uitzonde- ringsgevallen van de voortgezette controle, blijft het bij een bijstarn door een deskundige.

Steeds moet de accountant de leiding van het onderzock behouden en het verband leggen tussehen de verschillende gegevens, die het onderzoek oplevert.

Laten we ons overzicht van de literatuur ten slotte vooraf gaan door cen studie van het Reglement ran Arbeid van het Nederlandsch Instituut van Accountants. ${ }^{1}$ ).

Art. 7 van dit reglement luidt:

„Het balansonderzoek omvat het onderzoek naar de „bockhoudkundige juistheid der op de balans voorkomen"de bedragen en de juistheid der daarbij gegeven om,schrijuingen en naar het bestaan en de waardecring der ,activa en passiva.

„Indien cen lid, op grond van het vorenomsehreven ,onderzoek, van oordeel is, dat de balans een juist beeld "gecft van den toestand van het vermogen, waarop die ,balans betrekking heeft, onderteekent hij de balans, al ,of niet onder toevoeging eener toelichtende verklaring. „Een dusdanige goedkeuring der balans strelt zich „ten opzichte van het bestaan der lioopmansgoederen en gebruiksbezittingen, zoomede ten opzichte van de waur,deering der goederen en de afschrijvingen op die bezit"tingen, niet verder uit, dan van den niet-ter-zake-kun"dige verlangd kan worden."

Tot zoover art. 7 .

Op het eerste gezicht lijken de hier gecursiveerde woorden in flagranten strijjd met de bovenontwikkelde denkbeelden.

1)en accountant worden ten aanzien van het ,bestaan" de „,waardeering" en de ,afsch rijving" geen andere eischen gesteld dan van den nict-terzake kundige verlangd kan worden.

Zouden door deze woorden, de talrijke beroepen op hun eigen ondeskundigheid, die de accountants ter kennis van het publiek plegen te brengen, niet hun bevestiging vinden in het Reglement van Arbeid van de belangrijkste accountantsorganisatie hier te lande?

Naar mijn meening moet hier het volgende van worden gezegd.

We beginnen met vast te stellen, dat het ontwerpen en heoordcelen van een reglement van arbeid eigenlijk een juridische angclegenheid is. Natuurlijk is roor deze juridische angelegenheid een groote hoeveelheid speciale vakkennis (i.c. accountantsvakken) noodig.

Dit is niets bijzonders, zooals uit een enkel voorbeeld moge blijken. Wanneer de wetgever zich opmaakt tot een reglementeering van de sluitingsuren van de winkels in verschillende branches is een speciale vakkemnis van de onderhavige branches een volstrekt onontbeerlijk iets.

$\mathrm{Nu}$ is het waar, dat het reglement van arbeid slechts geldt binnen een private rechtsgemeenschap en dat de overheid zich van een en ander wcinig of niets aantrekt.

Maar dit moet verklaard worden nit het bedroevende feit, dat de overheid op dit terrein tot dusverre met haar wetgevenden arbeid hopeloos in gebreke is gebleven. Wanneer de overheid te dien aanzien deed wat door haar gedaan most worder, dan zou $\mathrm{er}$ een wettelijke regeling van het beroep tot stand lromen en het Reglement van Arbeid zou een stuk wetgeving van de overheid worden.

Deze, enigszins breedsprakige uitweiding, is hier opgenomen

1) De critische lezer zou terecht de vraag kunnen opwerpen of de Reglementen van Arbeid wel tot de vakliteratuur in den eigenlijken zin van het woord behooren.

Schrijver dezes zou een ontkennend antwoord op deze vraag in het minst niet verbazen, maar het groote practische belang, dat het R.v.A. voor den aanstaanden vakgenoot moet worden toegekend, heeft hem er toe gebracht deze materie toch hier ter plaatse aan de orde te stellen. 
ten einde den lezer er van te doordringen, dat het samenstellen en ook het lezen van ons Reglement van Arbeid stellig cen juridische aangelegenheid is en dat het dus volkomen geoorloofd moet worden geacht om hicr het juridische procédé van interpretatie ${ }^{1}$ ) toe te passen.

Fn bij cenig aandachtig lezen blijkt interpretatic hier wel zeer noodig: als er sprake is van ,,een goedkeuring, die zich nict verder uitstrekt dan van den niet-terzalie kundige verlangd kan worden" schept hier de dubbele negatie een vagheid, die a.h.w. tot interpretatie uitnoodigt.

Bepalen wij te dien einde allereerst onze aandacht tot de figuur van de ,niet-ter-zake-kundige" hieronder te noemen de ondeskundige.

Mocten we hieronder verstaan den man, die van de technische kemnis, die noodig is om een oordeel te vellen omtrent het bestaan der koopmansgoederen en gebruiksbezittingeen, omtrent de waardeering van goederen en omtrent afschrịjvingsquestios te eenenmale verstoken is en wiens oordeel over de onderhavige questies dus ten eenenmale waardeloos is?

De euphemistische wijze, waarop de samensteller van hot bewuste artikel spreekt van den ,niet-ter-zake-kundige " en dus blijkbaar het woord ondeskundige niet aandurft wettigt hot vermoeden, dat dit niet het geval kan zijn.

Inderdaad is het zoo, dat als wij hicr het begrip ondeskundigo opvatten in den zin van den man, dic om het nu eens populaiı: maar heel duidelijk te zeggen ,,van toeten noch blazen" wect. dat dan de geheele langademige alinea van artikel 7 zinnelons wordt van overbodigheid. Immers in dat geval zou er geen enkele tastbare verantwoordelijkheid voor den accountant kunnen worden geformuleerd en als dit bedoeld was zou de onderhavirge $2^{\circ}$ alinea van art. 7 ongeveer moeten luiden als volgt:

„Een dusdanige goedkeuring der balans strekt zich niet ,uit ten opzichte van het bestaan der koopmansgoederen ,en gebruiksbezittingen, evenmin ton opzichte van de ,waardecring der gocderen of de afschrijuing op die bc"zittingen".

Het is duidelijk, dat hier dus ecn volstrekte ondeskundigheid niet bedocld kan zijn.

Echter blijkt uit de woorden van het artikel expliciet, dat aan een rolledige deskundigheid evenmin gedacht is.

Het probleem, dat deze overwegingen ons oplevert, kunnen we nu als volgt formuleeren:

Interpretatie van den text van art. 7 R.v.A. levert ons cen vorm van deskundigheid, die het midden houdt tusschen volledige ondeshundigheid on volledige deshundighcid en die in den onderhavigen text vagelijk urordt aangeduid door het uoord „,niet-ter-zake-kundig." Is een dergelijke gedeeltclijke deskunheid een figuru, die in de theorie anvaardbaar en in de praktijk toepasbar is en is het ook mogelijk door het opsporen van andere gedeeltclijke deskundigheden, in andere vakken of in het accountantsberoep zelve, de figuur, door middel van deze analoge verschijningsvormen meer annemelijk te maken?

Beschouwen wij allercerst ons eigen vak. Fenige sociaaleconomische begrippen en eenig inzicht in juridische aangclegenheden zijn voor den accountant zeker onmisbaar. In overeenstemming hiermede heeft het Instituut dan ook deze vakken als examenvakken in zijn studieprogramma opgenomen. Kan nu de accountant q.q. als deskundige in deze vakken worden beschouwd? Er is niemand, die het zal willen beweren. Is hij volkomen ondeskundig? Ook dat kan men moeilịk volhouden.

Zeer klaarblịjkelijk heeft men hier een gedeeltelịke deskundigheid aanvaard. In hocverre deze zich dekt met de ,niet-terzake-deskundigheid" van art. 7 zal nog nader' moeten blijken.

2) De begrippen restrictieve interpretatie en extensieve interpretatie mogen bij de lezers van dit artikel bekend verondersteld worden.
Wellicht is het dienstig on reeds hier vast te stellen, dat we hier te maken hebben met zecr reëele dingen en niet met theoretische concepties, dic pour le besoin de la cause zijn gefantaseerd.

Een enkele casus moge dit aammemelijk maken.

Een accountant moet een balans verifieeren, waarop bịj do activa een hypotheek paraisseert. Wordt de accountant geacht naar een jurist te gaan om de hypotheekpapieren na te laten zien. Natuurlijk niet! Maar evenmin zal hij, wanneer later in die papieren een gebrek te voorschijn komt, zich op ondeskundigheid kumnen beroepen.

Wel degelijk erkennen hier practijk en opleiding een gedeeltelijke deskundigheid. Lin meer nog: deze gedoeltelijke deskundigheid leidt alleen dan tot vaagheden en moeilijkheden wanneer men deze el min of meer opzettelijk gaat inbrengen. Goede trouw en common sense zijn hier volkomen betrouwbare gidsen, die ons de natumrijke granzen niet uit het oog doen verliezen. Jat in de zeldzame gevallen van twijfel de zckerste weg (dus deskundig advies) de eenige juiste is spreekt evenzcer vanzelf als het iedere theoretische zwarigheid tot oplossing brengt. Ook buiten onze beroepsuitoefening komen dergelijke, ,gedeeltelijkdeskundigen" veelvuldig voor.

Ten einde niet te uitgebreid te worden volsta ik met een enkel voorbeeld.

Zoo is de medicus gedeeltelijk deskundig in tal van vakken, waarvan ik slechts noem chemie, biologie en physica.

Keeren wij nu naar ons eerste voorbeeld van gedeeltelijke juridische en economische deskundigheid van den accountant terug.

Mogelijkerwijze zal men tegenwerpen, dat de rechtswetenschap zoowel als de sociale economie den accountant dan toch mar speciaal onderwezen worden, maar dat dit met technologische vakken niet het geval is en dat wij dus op grond van deze analogie niet mogen concludeeren tot een gedeeltelijke technische deskundigheid van den accountant.

Dit argument houdt maar heel weinig steek.

Ik wijs er op, dat heden ten dage de meeste studeerenden in de accountancy in het bezit zijn van het einddiploma van een IJ.B.S. met 5 j. c. A. of B. en dat op deze scholen een belangrijke hoeveelheid physica en warenkennis of chemie wordt gedocecrd terwijl de H.B.S. A ook de wiskunde niet geheel verwaarloost en de H.B.S. B dit vak ecn ruime plaats toekent.

Uit hoofde van zijn vooropleiding beschikt de accountant over een zekere kennis, die hem ongctwijfeld in staat stelt om ook zonder specialisatie de techniek van de meeste productie processen te volgen.

Schrijvel dezes beschikt over een gedecltelijke deskundigheid op onderwijsgebied, maar aarzelt niet om te verklaren, dat de opleiding in de vakken wiskunde, chemie, physica en warenkennis bij den gemiddelden II.B.S. abiturient grondiger is, dan de juridische en sociaal economische, die de assistent accountant gemiddeld deelachtig wordt.

Bovendien vergete men niet, dat veel van de gedeeltelijke deskundigheid van den medicus evenzeer op H.B.S. opleiding berust.

Uit deze beschouwingen volgen nu de onderstaande conelusies.

1. De niet-ter-zake-kundige van art. $7 \mathrm{R}$. v. A. moet worden geinterpretecrd als een gedecltelijk deskundige, ander's heeft het artikel geen zin en zou er van geen enkele verantwoordelijkheid sprake kumnen zijn.

2. Deze gedeeltelijke deskundigheid wordt te dezer plaatse niet willekeurig bedacht, maar bestaat in andere tocpassingen reeds zeer lang en heeft in die toepassingen tot geen overwegende moeilijkheden aanleiding gegeven.

3. De gedeeltelijke deskundigheid eischt geen specialisatie; in- 
tegendeel is haar wezen van gedeeltelijke deskundigheid met het begrip specialisatie in strijd.

4. Gedeeltelijke deskundigheid kan worden verworven door voorbereidend onderwijs (H.B.S. b.v.) of door hooger onderwijs, waarbij dan de particuliere accountantsopleiding een tusschenfiguur voorstelt, die evenzeer gedecltelijke deskuridigheid oplevert.

5. Iloogstvermoedelijk is de hier ontwikkelde gedecltelijke deskundigheid de kennis, die de Amstendamsche School toolient aan de figuur, die zij noemt, ,verstandige leek". Hierover kan te dezer plaatse niet worden beslist.

Waarschịnlijk zal er diseussic voor noodig zijn om deze anillogie tot het cinde te onderzoeken.

(i. Als we terceht den verstandigen leek een gedecltclijke deskundigheid toekennen en op deze gedeeltelijke deskundigheid de mogelijkheid baseeren, dat de accountant-verstandige-leek de techniek van het productieproces volgt en voldoet aan de eischen van art. 7 moeten we ons afvragen of iedere accountant inderdaad over de gedeeltelijke deskundigheid beschikt, die we hier bedoelden.

Klarblijkelijk is dit niet het geval met den accountant, die de H.B.S. opleiding mist. Wel verre van deze jongelieden van de studie te willen uitsluiten lijkt mij toch, dat wij er op den duur niet aan zullen hunnen ontliomen om voor hen een zekere hoeveelhcid natuuructenschappelijke studic als examen-cisch (bij het examen algemcene ontuikkeling b.v.) te aanvaarden.

Uit bovenstaande beschouwingen en conclusies volgt, dat de niet-ter-zake-kundige van art. 7 de voorraden enz. zal helben te controleeren in den zin zooals het in den aanhef van dit artikel is uiteengezet volgens de theoretische opvattingen van de Amsterdamsche School, waarvan wij hier in het kort nog herhalen de uitspraak: Men kan van den accountant verlangen, dat hij doet, hetgeen in zijn vermogen ligt om de onderhavige technink te begrijpen en te bcoordeelen. Dit is het vertrouwen, dat hij in het maatschappelijk verkeer opwekt en men moet van hem verlangen, dat hij zijn functie abandonneert wanneer hij door bijzondere omstandigheden (een persoonlijke bijzondere ongeschiktheid om technische verschijnselen te beoordeclen b.v.) dit vertrouwen niet kan dekken.

Voor de goederenbeweging en de voorraden blijkt dien tengevolge de accountant verantwoordelijk te zijn in den zin zonals dit in den aanhef van dit artikel is uiteengezet; een opvatting die in overeenstemming is met art. $7 \mathrm{R}$. v. A.

Voor den opmerkzamen lezer zal nu nog een vraag onbeantwoord blijven.

Bij de inleidende beschouwingen hebben we de stelling aanvaard, dat ingeval de voorraad slechts met behulp van een zckere hoogere deskundigheid kan worden geteld enz. de accountant zich zal mocten doen bijstuan door een deskundige.

Klaarblijkelijk is dit van toepassing op de gevallen, waarin cen gedeeltelijke deskundigheid onvoldoende moet worden geacht.

Is er nu geen verschil tusschen de opvattingen van de Amsterdamsche School en de gedachten neergelegd in art. 7 ?

Naar aanleiding van dit vragpunt zou ik het volgende willen opmerken. Reeds dadelijk hebben we opgemerkt, dat de gevallen waarin de gedeeltelijke deskundigheid of - hetgeen waarschijnlijk hetzelfde is, de kennis van den verstandigen leek - onvoldoende zijn om den voorraad rationeel te controleeren zeldzame uitzonderingen zijn.

In ieder geval mag dus art. 7 nooit uitgaan van de noodzakelijkheid van deskundigen bijstand omdat dan de fout gemaalit zou worden van het verheffen van cen uitzondering tot regel.

Toegegeven kan dus worden, dat er waarschijnlijk in abstrac- to geen bezwaar zou behoeven te bestaan om aan het onderhavige artikel een alinea toc te voegen, die ongeveer als volgt zon kumnen luiden :

Wanneer en voorzoover de aard der koopmansgoederen en gebruiksbezittingen, ter beoordeeling in den zin van do vorige alinea bedoeld, een zoo speciale deskundigheid ve!eischen, dat moet worden aangenomen, dat de accountant als zoodanig geen rationecle controle kan uitoefenen, moct hij zich bij ziju controlewerkzaamheden docn bijsta:u door een door henzolf aan te wijzen deskundige.

Doze deskundige zal in geen geval in eenige afhankslijke betrekking mogen staan tot de gecontrolecrde bedrijfshuishouding.

Intussehen wil het mijj voorkonen, dat in de practijk ecn dergelijke invoeging toch wel gemist kan worden en daarom ook inderdaad als overbodig en dus als schadelijk moet worden beschouwd.

Ik ga hierbij nit van de volgende overwegingen.

$1^{\circ}$ De interpretatie, die we tot dusver van art. 7 gegeven hel ben. leidt onafwijsbaar tot de conclusie, dat de accountant een zekere verantwoordelijkheid voor de voorraden enz. draagt.

$2^{\circ}$ Volgens art. 1 R. v. $\Lambda$. moet de accountant ,op gocde gronden overtuigh zijn van de juistheid der medegedeelde nitkomst."

$3^{\circ}$ Combineeren wij nu de punten 1 en 2 met het geval, dat er een deskundigheid vereischt is, die de normale gedeeltelijke deskundigheid warvan hier steeds sprake is to boven gaat, dan hebben we inmpliciet erkend, cat in deze nitzonderingsgevallen geen andere mogelijkheid overblijft dan het aanvaliden van deskundigen bijstand.

Dit is cen geval van extensieve interpretatie van art. 7 dat mij juist door zijn groote soepelheid ver verkiesbaar lijkt boven het vastleggen van fijne onderscheidingen in een star wetsartikel, dat juist door zijn starheid toch niet in staat zal zijn om de subtiliteit van de werkelijkheid, die we hier trachten weer te geven evenzeer te benaderen als een goed doordachte interpretatie en jurisprudentie ons mogelijk maken.

Intussehen moeten we het bij deze opnerking laten: een nadere uitwerking van deze gedachte ligt niet in de bedoeling, die met dezo literatuuroverzichten wordt nagestreefd.

Concludeerend stellen we dus als resultaat van dit eerste artikel vast:

Mits cxtensief geïnterpreteerd is art. 7 R.v.A. van het N.I.v. A. in overecnstemming met de theoricën van de Amsterdamsche School.

Over de cigenlijke literatuur zal in volgende artikelen gehandeld worden.

DrS. S. KLEEREKOPJTY

\section{BELASTINGVRAAGSTUKKEN} Red.: W. WESTRA

(Bijdragen en mededeelingen zende men aan den Secretaris der Redactie)

\section{Artikel 4 der Omzetbelastingwet 1933}

Dit artikel luidt: „Op ver"zock van fabrikanten, die tevens het beroep van handelaar uitoefenen, kan Onze Minister van Financiën onder door hem te stellen roolwaarden toestaan, dat de overdracht van goederen uit de fabrieksafdeeling naar do handelsafdeeling wordt beschouwd als een levering krachtens overeenkomst van koop en verkoop." 